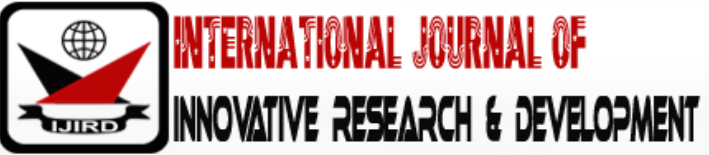

ISSN 2278 - 0211 (Online)

\section{Strategies Supporting Institutionalization of Cash and Voucher Initiatives in Humanitarian Responses in Turkana County, Kenya}

Moses Edapal Nawoton
Masters Student, Emergency Management Studies,
Masinde Muliro University of Science and Technology, Kenya
Dr. Ferdinand Nabiswa
Lecturer, Emergency Management Studies,
Masinde Muliro University of Science and Technology, Kenya
Dr. Edward Mugalavai
Lecturer, Disaster Management and Sustainable Development,
Masinde Muliro University of Science and Technology, Kenya

\begin{abstract}
:
Coordination of cash transfer programs (CTP) is very important in achieving better humanitarian assistance in times of disasters and emergency because it saves resources, avoids conflicts, evades duplications and gaps, minimizes the difference between programs as well as thwarts inflation to local markets. The use of CTP to provide humanitarian assistance so that people access goods and services they need before, during and after crisis has been gaining momentum particularly since 2010. However, absence of a structured coordination framework of CTP has created lapses in the initiative thereby resulting into duplication of interventions, resource gaps, fragmentation and mismanagement of resources in quality service delivery. The study sought to examine strategies that support institutionalization of cash and voucher initiatives in humanitarian actions in Turkana County. The study adopted evaluation research design. Sampling strategy incorporated four techniques: multistage, proportionate, purposive and simple random sampling methods. A sample size of 382 was used in this study. Data was collected using questionnaires, interview guides, FGD, key informant interviews (KII) and direct observation (DO). The data collected was coded and analyses by both descriptive and qualitative methods using Statistical Package for Social Science (SPSS). The study found out that strategies for institutionalizing CTP included establishment and use of CTP legal and regulatory framework, advocacy and lobbying for the use CTP by CaLP, role of Cash Working Groups in CT coordination and research and advocacy for CTP.
\end{abstract}

Keywords: Cash transfer program, humanitarian responses, coordination

\section{Introduction}

All forms of humanitarian assistance need to be coordinated to make the best use of resources and avoid duplicating efforts. But with multipurpose cash disrupting traditional divisions of responsibility in the humanitarian sector, disagreements remain around how Cash and Voucher Assistance should be coordinated" (CaLP, 2014)

Coordination of cash transfer programs (CTP) is significant in achieving better humanitarian response in times of emergency as well as link emergency and development responses. Synchronization of CTPs avoids conflicts, minimizes differences among programs, avoids duplication and gaps between CTP and non-CTP aid interventions, avoids inflation of local markets and save resources (Gabrielle, 2015).

Cash Transfer Programming (CTP) refers to all programs where cash or vouchers for goods or services are directly provided to beneficiaries. In the context of humanitarian assistance, the term is used to refer to the provision of cash or vouchers given to individuals, household or community recipients; not to governments or other state actors. CTP covers all modalities of cash- based assistance, including vouchers (Mc Cormack, 2018). The term can be used interchangeably with Cash Based Interventions (CBI) and Cash Based Transfers (CBT). The key objective of cash transfer is to increase the real income of beneficiaries in order to enable a minimum level of consumption within the household (CaLp, 2014). United Nations (2009) discussed CTPs under human right as non contributory programmes providing payments in the form of cash to individual or household with the primary objective of increasing real income in order to enable minimum level of consumption.

History traced the origin of Cash transfer programmes (CTP) as a component of social protection way back to 1990 in Europe (Teixeira, 2009). Since then, CTP has been launched in a growing number of developing countries 
including Latin America, Asia and Africa. The programs are increasingly providing evidence that CTP can help tackle hunger, increase living standards, improve education and health and thus break chronic cyclic intergenerational poverty.

There has been an incessant increase in use of CTP in the humanitarian sector particularly since 2010. According to Collins (2012), the range of actors providing cash based initiatives (CBI) has subsequently been on the rise thereby translating into huge amounts of money transacted in the absence of a structured framework of cash transfer programming, the chances of double dipping, logistical losses, fragmentation and mismanagement of resources in service delivery is likely to occur.

Cash Learning Partnership (2013) summarized humanitarian response transfers modalities and delivering mechanisms. Transfer modalities include in-kind, cash transfer, voucher and combination of the three while delivering mechanism comprised of mobile money, financial service providers, retailers/vendors and direct cash. Cash transfer can be provided with or without conditions (conditional or unconditional) whereas cash or voucher utilization by beneficiary can be restricted or unrestricted to certain commodities. Kaufman (2012) underscored why cash; alternative to in-kind assistance, market-based solution, enhance recipient dignity, empower beneficiaries as well as most effective and efficient method of delivering humanitarian assistance. ODI (2015) pinpointed that though the use of cash transfers and vouchers in humanitarian response is increasingly growing due to their efficiency and effectiveness, they remain small proportion of humanitarian aid. IFRC (2014) identified risks of uncoordinated approaches of cash transfer namely trigger tension, reduce effectiveness and efficiency as well as risk of gaps and duplications. The coordination system as it is presently being implemented (typical structures, roles and responsibilities) is not adequate to ensure a more holistic approach to meeting the needs of persons affected by crisis. Thus, Cash coordination needs should clearly be defined and predictable allocation of leadership responsibilities while strengthening the capacity of the humanitarian system to coordinate cash transfers (CaLP, 2015).

UNICEF (2015) pointed out that Cash transfer is one modality among a range of social protection interventions and that predictable direct transfers to individuals or households protect them from shocks and support the accumulation of human, productive and financial assets. Jowett (2014) indicated that since the 2004 Indian Ocean Tsunami, there has been a progressive trend within the humanitarian sector at large to use cash transfers as a programme modality in times of emergencies and for recovery in both conflict and disaster contexts. A number of reviews and research studies have been undertaken that aim to explore the strategic, institutional and operational challenges to support appropriate cashand voucher-based interventions. These studies have built a knowledge base for CTPs, including understanding of the different cash modalities, the roles of diverse stakeholders, and the opportunities as well as the challenges in taking cash to scale.

The nature of humanitarian crises is changing: more people are in need of assistance for longer period of time putting the humanitarian system under severe strain. This forces humanitarian sector to use other appropriate strategies such as CTP to protect the lives and dignity of those affected (Collins, 2012). Cash Transfer Programming has been used in recent humanitarian responses such as the Earthquake in 2010 in Haiti, Pakistan and various other countries in the world (Burke et al., 2014). This brought into perspective the need to consider structured coordination of these humanitarian actions in order to achieve their shared humanitarian objective. Jehan (2016) observed that between 2010 and 2013, the number of African countries with unconditional cash transfers doubled to 40 nations and noted that cash transfer facilitates the link between humanitarian and development.

The state of world cash report (2018) described coordination of cash Transfer programming being unreliable limiting benefit realized. It highlights confusion about where CTP coordination sits in international system as well as limited commitment to use shared operational mechanisms. The report argued that CTP coordination remained ad hoc and contested undermining efficiency and effectiveness of cash-based initiatives. Marito et al., (2012) reported the rise of CTP in Sub Saharan Africa assimilates results of thorough review of recent use of Cash Transfer Programs in Sub Saharan Africa.

The constitution of Kenya (2010) chapter four compressively emphasises the bills of rights which by extension include rights of every citizen to social security and mandates the state to provide social security to people who are vulnerable. On this regard, Kenya is implementing Hunger and safety net program (HSNP) that provides regular cash transfer to vulnerable groups of people in Kenya inter alia; elderly, orphan and vulnerable Children (OVC) and people living with severe disability (GOK, 2010). Kenya National Disaster Risk Management (DRM) Policy 2017 outlines the need for establishment, streamlining of DRM institutions, coordination frameworks, partnership and regulation in Kenya (GOK, 2017). Social Protection Policy 2011 is linked to a social pillar of Kenyan vision 2030 which indicated that poverty, marginalization and vulnerability as key challenges that trapped Kenyan people in chronic intergenerational and cyclic poverty. The policy outlined its goal of ensuring that all Kenyans live in dignity and exploit their human capabilities for their own social and economic development (GOK, 2011). Similarly, national social protection strategy 2014 recognizes and appreciate cash transfers as core social protection intervention in Kenya (GOK, 2014). National Social assistance act 2013 holds that social assistance including cash transfer is provided to persons in need and for connected purposes (GOK, 2013). Krystle (2015) reported that although Kenya has made strides in terms of economic development and increase access to health and education, $45.9 \%$ of the population continue to survive on 1.25 dollar per day. Therefore, the state has invested in development of social Assistance measures such as CTP as a means of providing support to poorest and most vulnerable household in Kenya. Karen (2017) reported that though cash as humanitarian intervention is growing very rapidly in Kenya, it is not clear where cash interventions are best placed within the sector working group coordination structure.

UN women (2015) pinpointed that Turkana is one of Kenya's most disaster-prone counties with regular exposure to several natural and human-induced catastrophes or hazards, causing high economic and human losses. This County has 
over a long period been involved in many in-kind social protection programmes targeted to specific needy groups. Presently, the Kenyan Government and non-state actors are implementing a number of cash transfer initiatives (NDMA, 2016). In Turkana County, the national government has since implemented four social assistance programmes, namely the Orphan and Vulnerable children (OVC) 2005, Older Persons Cash Transfer (OPCT) 2006, Hunger Safety Net Programme (HSNP) 2007 and People with Severe Disability Cash Transfers (PWSD-CT). Turkana County Emergency and Disaster Act 2016 provides for more organization of the mitigation of, preparedness for, response to and recovery from emergencies and disasters in the county. Additionally, Turkana County DRM policy 2017 is clear on creation of an effective framework through which Disaster Risk Management is entrenched in all aspects of the county development plans leading to safe and disaster resilient county with robust disaster risk management system that contributes to the protection of lives, livelihoods, property and the environment (TCG,2017).

In spite of above programmes that have been in place since 2015, there is little compelling evidence that the County of Turkana is coming out of vulnerability position from dynamics of disasters. This research endeavored to establish whether instituting coordination mechanism on ongoing cash transfer programmes could make it effective and have tangible impact and move Turkana County out of vulnerability crunch.

\section{Theoretical Framework}

\subsection{The Theory of Coordination}

The theory of coordination was advanced by Malone (1994) who defined Coordination as the process of management of conflicting dependencies between components of coordination such as goal, actors, activities and resources. He categorised these components into task (goal plus activities) and resources (actors plus resources). The relationship between resources and task create network of dependencies that are either facilitative or conflicting in nature. It is argued that complex conflicting dependences between resources and task generate a coordination problem managed by establishing coordination mechanism (Malone, 1994). The theory of coordination is defined differently according to variety of fields (Malone and Crowston (1994); IFRC (2004); CaLp (2009); Chandler (1962); Omuterema (2003); (Thomas W. Malone, 1988)).

Coordination is a process of managing dependencies between activities. This is the theoretical framework for analysing coordination as a complex process thus contributing to user task analysis and modelling. The framework looks at actors, tasks, interdependencies and created resources. The linkage is that actors performing interdependent tasks create resources of various types. The key elements of the theoretical framework according to Malone (1994) include goals, activities, actors and interdependencies as indicated in Table 1. According to Crowston et al. (1998), coordination problem requires establishing coordination mechanism relying on group functions such as decision-making, communication, shared understanding, coordination and collective sense making.

\begin{tabular}{|c|c|}
\hline Components of Coordination & Associated Coordination Processes \\
\hline Goals & Identifying goals \\
\hline Activities & $\begin{array}{c}\text { Mapping goals to activities (e.g., goal } \\
\text { decomposition) }\end{array}$ \\
\hline Actors & Selecting actors \\
& assigning activities to actors \\
\hline Interdependencies & "Managing" interdependencies \\
\hline \multicolumn{2}{|c|}{ Table 1: Components of Coordination } \\
Source: Malone, 1994
\end{tabular}

The main claim of coordination theory is dependencies and mechanisms for managing them. Malone et al. (1999) and Crowston (2003) analysed dependencies as tasks and actors using specialised skills to deliver, and producer or customer creating a resource required by another actor. This dependency normally divided into three sub dependencies namely usability, transfer and precedence. The usability means that the resource created by the first task must be appropriate for the needs of the second task while transfer indicate that the resource must be moved from where it was created to where it is consumed. Finally, precedence means that the actor performing the second task must learn when the resource is available and when to start the task.

To overcome these coordination problems, actors must perform additional work, which Malone and Crowston (1994) called coordination mechanism such as standardization, direct supervision and mutual adjustments. In summary, different dependencies interact through processes that create coordination problem manageable by creating a coordination mechanism.

\section{Methodology}

The study adopted evaluation research design (Table 2). This research design entails measurement of the implementation and outcomes of the Programmes (Barbie and Mouton, 2010). Evaluation design was adopted in this study because it indicates effects of development programmes on social wellbeing of beneficiary households. For this study, evaluation design was appropriately employed to evaluate the effects of cash coordination on effectiveness and efficiency of CTPs to beneficiaries' households in Turkana County

The study population comprised of five categories of respondents: local administration, CT beneficiaries, nonbeneficiaries, and key stakeholders that included major government officers, managers of humanitarian agencies, donors 
and managers of financial institutions. Local administration incorporated MCAs, ward administrators, deputy county commissioners and chiefs. Beneficiaries and non-beneficiaries of CT were majorly women and thus apparent respondents in this category. Those engaged during FGD were purposively selected from the local administration, CT beneficiaries and non-beneficiaries. Across these categories, gender, vulnerable groups, age categories including the youth and elderly members were considered throughout the study. All respondents were drawn from three sub-Counties of Turkana East, North and Central because of varied vulnerability and humanitarian interventions coverage the sample frame for population for the three Sub Counties was as indicated in Table 2.

\begin{tabular}{|c|c|c|c|c|}
\hline Sub County & Population & $\begin{array}{c}\text { Total } \\
\text { Households }\end{array}$ & $\begin{array}{c}\text { Non CT Beneficiaries } \\
\text { Households }\end{array}$ & $\begin{array}{c}\text { CT Beneficiaries } \\
\text { Households }\end{array}$ \\
\hline Turkana North & 129,087 & 18,441 & 12,418 & 6,023 \\
\hline Turkana central & 134,674 & 19,239 & 12,955 & 6,284 \\
\hline Turkana East & 90,466 & 12,924 & 8,703 & 4,221 \\
\hline Total & 354,227 & 50,604 & 34,076 & 16,528 \\
\hline
\end{tabular}

Table 2: Distribution of Study Population Census, the Sample Frame

Source: Census, 2009 and NDMA 2017

\section{Findings}

\subsection{Questionnaire Return Rate}

Through research assistants, the researcher directly administered a total of 382 questionnaires to sampled households' heads: 191cash transfer recipients and 191 non cash transfer recipient. Key informant interviews and focus Group discussion were also conducted. The return rate of the questionnaires was $382(100 \%)$ as captured in the Table 3

\begin{tabular}{|c|c|c|c|}
\hline $\begin{array}{c}\text { Respondents } \\
\text { Questionnaire }\end{array}$ & $\begin{array}{c}\text { Sampled } \\
\text { Population }\end{array}$ & $\begin{array}{c}\text { Sample } \\
\text { Response }\end{array}$ & Percentage \\
\hline CT recipients HHs heads & 191 & 191 & 100 \\
Non recipients HHs heads & 191 & 191 & 100 \\
Focus Group Discussion & 3 & 3 & 100 \\
Key informants' interviews & 44 & 42 & 95.45 \\
\hline
\end{tabular}

Table 3: Questionnaire Return

Source: Author, 2017

\subsection{Established Legal and Regulatory Framework}

The respondents were asked about their knowledge on existence of established legal and regulatory framework as a strategy in place to boost efficacy of cash and voucher initiatives (Cash transfer) within Turkana.

Global humanitarian response landscape continued to experiences rapid changes that have generated challenges in global humanitarian system. As such humanitarian and CTP has radically changed over the past few decades. It follows, then, that cash transfer programming is increasingly becoming preferred and default modality in humanitarian actions where various actors, sectors and governments are getting involved raising the question of cash coordination.

Kenya is a signatory to international legal frameworks for humanitarian actions: international humanitarian law (IHL), international human rights law (IHRL), international refugee law (IRL), international criminal law and international Disaster Response laws, rules and principles (IDRL). Of special consideration is IDRL that emphasizes on importance of humanitarian assistance in disaster context highlighting need for regulatory framework used in delivery of humanitarian assistance that is comprised of comprehensive legal framework and developed coordination. Additionally, IHRL emphasizes the right to life indicating the right to humanitarian assistance and that various economic and social rights guaranteed legal space for individual to claim the right to humanitarian assistance. Furthermore, IHL obligated parties to conflicts primary responsibility of providing humanitarian assistance to civilians under their control and recognised the right to humanitarian assistance. In brief, these frameworks not only provide guidance on how to address humanitarian situations, but can also serve as powerful tools for advocating for, achieving and protection of affected civilians (GSDRC, 2013).

Many countries in sub Saharan Africa have been substantively planning a head to establish social protection legal and policy frameworks in order to invest in the long-term economic development. Cash transfer coordination would therefore, provide both technical and strategic unified direction to cash transfer programmes purposely to achieve their joint and shared goals. The existing CTP coordination system is fragmented globally while operates in ad hoc in Kenya. The system experiences shortcomings such as delays, resources gaps, duplication, and created tension between agencies. This makes the findings of this study useful in narrowing down to solve these challenges. Given expanded ASAL areas in Kenya that often require CTP as a remediation to disaster shock and stress, the findings of this study provide until then a missing empirical evidence on how disputed cash Coordination could be weakening CTP in ASAL using Turkana County (Burke, 2014). 
Based on literature review, the existing legal and regulatory framework in Kenya to guide cash transfers had a national and global outlook. At national level, there was Kenya Social protection policy 2011 and Social Assistance Act 2013 (GOK, 2011) while it was also established that Non-governmental organizations (NGOs) players used a framework with a global touch. For instance, united Nations High Commissioner for Refugees (UNHCR) used UNHCR strategy for institutionalization of cash-based interventions 2016-2020 as action plan to implement its policy on Cash-Based interventions. Similarly, CaL P used Cash Focal point approach in which cash experts are deployed to a country to support cash programming. The UN agencies other than UNHCR used cluster system in which UN country team has created separate cash programming including cash cluster appeals for funding and reporting mechanisms.

The research sought the knowledge of respondents on the extent to which these aspects of legal and regulatory framework have been institutionalized to guide cash transfer programming in the county. Their response is as captured in Figure 1

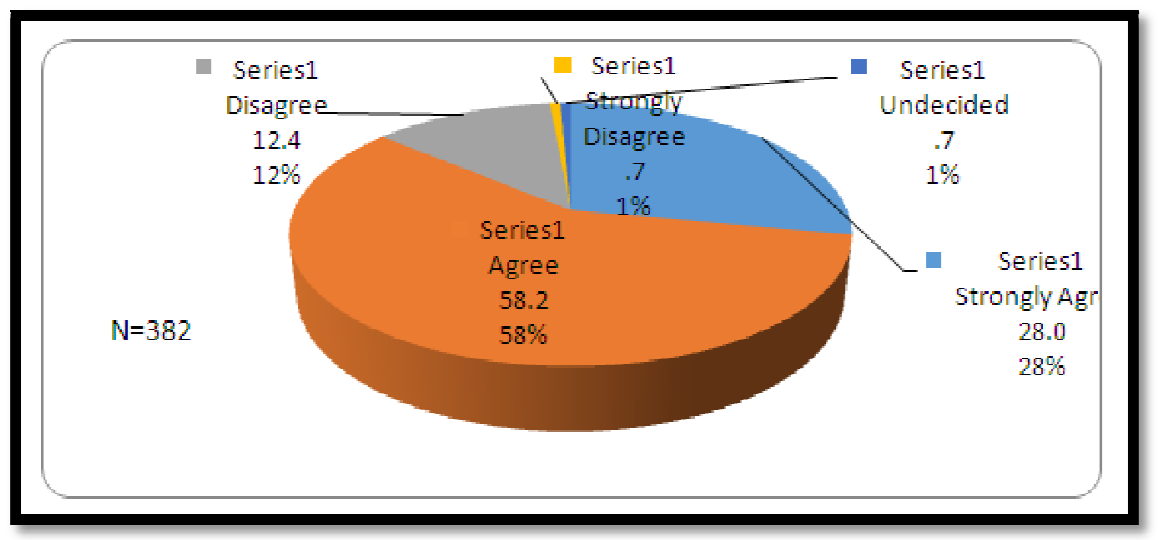

Figure 1: Established Legal and Regulatory Framework Source: Field Data, (2018)

The findings in Figure 1 revealed that 107 (28\%) of the respondents strongly agreed, 221(58\%) agreed, 46(12\%) disagreed, 4(1\%) strongly disagreed and 4(1\%) undecided. This study found that majority $330(86 \%)$ of the respondents were in agreement that legal and regulatory framework existed and had huge bearing on the institutionalization of cash and voucher transfer programmes. However, around $50(13 \%)$ respondents had contrary view on significance of regulatory framework as strategy of institutionalizing cash and voucher programmes. This contrary view could be taken to mean that a section of community members is unawareness of existence of strategies to institutionalize cash and voucher transfers. It could also indicate the low level of understanding among respondents especially non recipients of CT about the role of legal and regulatory framework in formalizing cash and voucher interventions in humanitarian responses in Turkana county. The study found from key informant interviews that establishment of CTP in any institution depends on whether or not it is enshrined in policy and legislative framework. If it is backed by the regulatory framework, then it gets funded and gains other support for operationalization.

From Focus group discussions and key informant interviews, it was noted that cash and voucher programmes are new initiatives and that plans are underway in many countries to establish legal and regulatory frameworks. During focus group discussions, one of the participants expressed this voice:

The use of cash transfers in humanitarian assistance is a new Idea. Even regulations have not been formulated. Some counties are formulating policies and bills on social protection. Counties are using existing Kenya social protection policy. I think NGOs use international guidelines and tool kits on cash transfer. But I hope laws of host country prevail over global ones (FGD participants, 25th march 2018).

This view was also echoed by one key informant from UNICEF official: Most countries lack polices and legislations necessary to regulate CTP. They use cash transfer programming tool kit to design and implement cash and voucher interventions (UNICEF official, 22 $2^{\text {th }}$ March, 2018)

The thinking of focus group discussions and key informant interview are in agreement with Kerry et al. (2012) who asserted that the use of cash transfers to assist poor and vulnerable households in resource - poor countries is relatively a new concept in many African countries.

The findings are in agreement with GOK $(2011 ; 2013)$ which observed that though Kenya has no CTP regulatory framework, social protection policy 2011 and Social Assistance act 2013 are referred to when seeking for direction and guidance regarding institutionalization of cash transfer programming. While in some cases CTPs are institutionalized and incorporated into national Social protection strategies through domestic laws, others are based on presidential degrees, policy statements and operational manuals and guidelines. Countries such as Chile and Brazil reported existent of CTPs legal provisions regulating their programmes (Carmona, 2009). Nevertheless, the issue of possibility of cash transfer provision creating dependency syndrome among beneficiaries was raised by Sherpherd et al., (2011) who put out argument around dependency that evidence show that social assistance support savings, human capital, investments \& enterprise, improve labour market participation and reduce dependency in the long term

Similarly, Amina and Abdalla (2015) reported that Marsabit County enacted legislation and developed policy framework that provides for undertaking of CTP for both emergency and non-emergency settings. The Public Financial Management 
Regulation 2015 establishes Marsabit County Social Protection (SP) fund that aimed at providing regular CT for vulnerable households as part of an institutionalized SP programme by the county.

From Focus group discussions and key informant interviews, it was noted that cash and voucher programmes are new initiatives and that plans are underway in many countries to establish legal and regulatory frameworks. This is indicated by the voice from one of the participants; I think the use of cash transfers in humanitarian assistance is a new idea and even regulations have not been formulated. Some counties are formulating policies and bills on social protection. For instance, Counties are using existing Kenya social protection policy and international guidelines on cash transfer (FGD participants, 25th march 2018) This view was also echoed by one key informant from UNICEF official: Most countries lack polices and legislations necessary to regulate CTP. They use cash transfer programming tool kit to design and implement cash and voucher interventions (UNICEF official, 22th March, 2018)

Most focus group discussions and key informant interviews were in agreement with Kerry et al. (2012) who asserted that the use of cash transfers to assist poor and vulnerable households in resource - poor countries is relatively a new concept in many African countries.

\subsection{The Role of Cash Learning Partnership in CTP}

The respondents were asked about their knowledge on role of CaLP as a strategy in institutionalizing Cash transfer programs in Turkana. Their responses were as indicated in Figure 2.

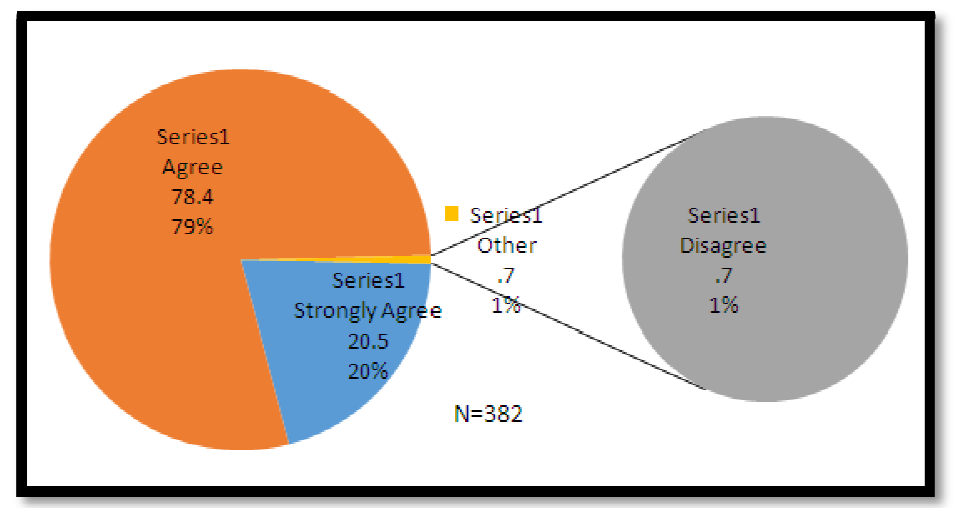

Figure 2: The Role of Cash Learning Partnership in CTP

Source: Field Data, 2018

The findings in Figure 2 revealed that majority $302(79 \%)$ of the respondents agreed while $76(20 \%)$ strongly agreed as $4(1 \%)$ disagreed. The findings found that most $380(99 \%)$ of the respondents appreciated the role of Cash Learning Partnership as strategy of formalizing CTP in Turkana county. This then means that most people in Turkana county were aware of existence of CaLP and its role of strengthening capacity of cash transfer programmes by way of supporting its institutionalization in their counties, regions and continents.

These results are in agreement with CaLP (2014) which stated that CaLP is a global partnership of humanitarian actors engaged in policy, and research within cash and voucher assistance (CVA) and that it is based on learning, knowledge sharing, networking, policy and coordination around CVA in humanitarian context. Similarly, Kaufmann et al. ( 2012) pointed out that CaLP as well as international Federation of Red Cross (IFRC) are the two global organizations that promote and advocate for CTP in humanitarian sector and that CaLP aims at improving knowledge about cash transfer programming as well as their quality throughout the humanitarian sector.

Key informants and two FGDs also reported the presence of CaLP in ASAL counties engaged in capacity building of actors formalizing CTP. One key informant from Save the Children indicated; I remember in 2015 when I attended two trainings organised by CaLP for one week each in Lodwar. The trainings were on Coordination for Cash Programming in the ASALs (Module I) and Including Cash Programmes in Contingency Planning and Preparedness (Module II). Participants were awarded certificates of training (Save the Children official, 22 th March, 2018).

The key informant voice was supported by Amina (2015) who reported that a 5-day training that drew participants from state and non-actors was conducted by CaLP in Marsabit and Turkana counties focusing on CTP and coordination.

Focus group discussions with the heads of households from Turkana North reached general consensus that the training of actors including the community members on cash transfers has in the recent past improved. One FGD from Turkana East reported: Community awareness is usually conducted by agencies implementing CTP. As a community, we are aware of targeting process, eligibility criteria, payment process, transfer amount and even key actors.

In light of the above FGD voice, it is clear that capacity building on cash transfer programming is evident and that it has boosted institutionalization of cash and voucher interventions resulting in improvement of quality, effectiveness and efficiency of such programmes. This view is supported by Nicola et al. (2013) who reported about FGDs in Uganda and Kenya that had community and beneficiaries with high knowledge and understanding of CTP key issues such as payment processes, eligibility criteria, transfer value and transfer delivering mechanisms. 


\subsection{Cash Working Group (CWG)}

The respondents were asked about their knowledge on Cash Working Group as a strategy for institutionalizing Cash transfer programs in Turkana. Their responses were as indicated in Figure 3.

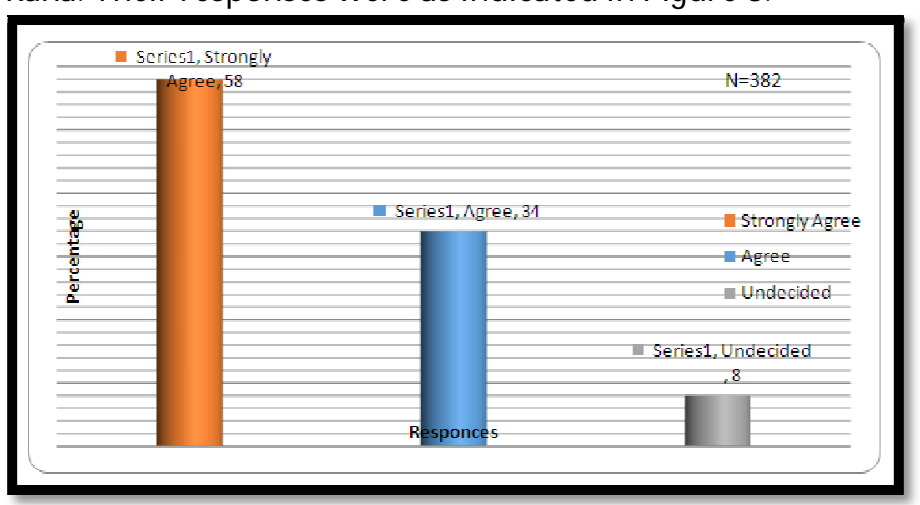

Figure 3: Cash Working Group (CWG)

Source: Field Data, 2018

The results in Figure 3 indicated that most 222 (58\%) of the respondents strongly agreed, 130 (34\%) agreed while $30(8 \%)$ were undecided. The findings reveal that most of the respondents strongly believe that CWG, if effective and efficient, may reinforce institutionalization of CTP. This means therefore, since CT is increasingly becoming preferred and default option in humanitarian response, various donors and actors participate in this sector which ultimately requires CWG that plays coordination role resulting in institutionalization of effective and efficient cash and voucher programmes. As supported by WB (2016) where clarified the function of CWG as a central point for overall technical support and sharing of information such as support standards, ways of working and identifying opportunities for common programming approaches.

These findings are in agreement with Kenya CWG (2017) which confirmed that CWG in Kenya was first formed in 2017 when agencies working on CTP identified lack of coordination as a major concern and agreed to establish a coordination forum. In Africa, CaLP (2018) reported one meeting where CWGs shared experiences and learning from Burundi, Ethiopia, Kenya, Madagascar, Tanzania, Somalia, South Sudan, Sudan and Uganda. The meeting provided insights that were likely to be of interest to anyone involved in discussion about coordination of cash-based assistance. Globally, Cash Working groups begin being established as from 2014 and its major role is to coordinate establishment and implementation of CTP (Beirut CTPWG, 2014).

\subsection{Research and Advocacy}

The respondents were asked about their knowledge on research and advocacy as a strategy for institutionalizing Cash Transfer Programmes in Turkana county. Their responses were as indicated in Figure 4

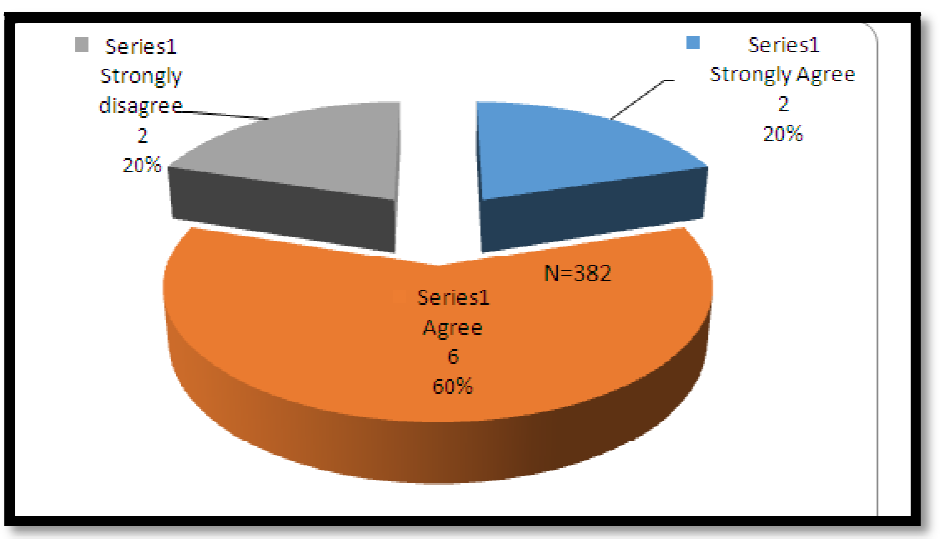

Figure 4: Research and Advocacy

Source: Field Data, 2018

The findings in Figure 4 revealed that 76 (20\%) of the respondents strongly agreed, 230 (60\%) agreed and 76 (20\%) strongly disagreed that Research and advocacy plays a key role in institutionalizing Cash Transfer programs in Turkana country. The study found out that research emerged as one of the areas that had helped in supporting formalization of the cash transfer programs based on the fact that a lot of information that was arrived at to help in facilitating the programs were acquired through research. The decision to give cash to specific communities was not just made randomly but through proper research in the target areas so as to find out which households within communities were needy and as such the findings helped in advocating for the programs to target the people who needed more help as opposed to just settling for any person in these communities. The findings do agree with Collins (2012) who asserted that research and advocacy are critical in CTP by way of advocacy purpose, justification for adoption of CTP, feeding lessons and good practices into current and future CTP programming. The key stakeholders involved in the cash transfer 
programs indicated that they conducted proper research before deciding on the process of rolling out these cash transfer programs. In an interview with an official from Oxfam Kenya it was reported that; We do not just go offering aid in form of CT to anybody without first conducting proper research to find out who is needy and who is not. This is because we know that there are people who may attempt to take advantage of the situation and benefit from these programs even though they may not be deserving. Therefore, research and advocacy are a key aspect of our activities especially in the first stages of our operations in various places (Oxfam Official, 20th March, 2018).

In further support of the findings, another official from world vision Kenya revealed that; Research and advocacy are a key component of our cash transfer programs based on the fact that, it only through research that we can find vital information relating to the needs of the community and give them proper support. It would not be prudent for us as humanitarian agencies to pretend the that we know all the needs of our target communities without actually going to the communities and conducting needs assessment to help us in decision making (World Vision official, 25 th March 2018).In broader perspective, advocacy is an effort to encourage other actors to consider cash transfer programming as a response option alongside other forms of responses depending on context (Mountfield, 2013). Further support of advocacy is provided by CaLP (2012) which argued that cash transfer is a new way of delivering aid and there is need for practitioners to make a case for CTP as well as address fears across different audiences.

\section{Conclusion}

The study concluded that though various strategies for institutionalizing cash and voucher initiatives were available, Turkana County has not institutionalized its cash and voucher initiatives owing to political unwillingness and low weight put on prioritizing such programmes. As such Turkana county government has not established legal and regulatory frameworks that facilitate the institutionalization of CTP.

\section{Recommendation}

The study recommends that the Turkana county government should formulate a social protection policy, bill and regulations in order to establish regulatory frameworks within which CTP may be instituted and coordinated. Currently coordination of CTP seemed to be based on ad hoc and not enshrine in any policy and legislation frameworks. It is therefore, very important to institutionalize such programmes because they should be well regulated and coordinated resulting in greater quality, effectiveness and efficiency in service delivery

\section{References}

i. Amina and I. Abdulla, S. (2015). Cash Transfer Programming in ASALs areas of Kenya. Nairobi, Kenya: Oxfam p.23 $-54$

ii. Burke,J. (2014). Coordination and Cash transfer: Fit for the Future. London, UK: Kings College.

iii. Burke, J. (2014). Is Cash Transfer Programming Fit for Future, London, UK: Kings College London

iv. Collins, O. (2012). Review of Emergency Cash Coordination Mechanisms. Plaisians: Cash Learning Partnership.

v. Collins, O. (2012). Review of Emergency Cash Coordination Mechanisms. Plaisians: Cash Learning Partnership

vi. Gabrielle, S. (2018) The State of the Worlds Cash Report: Cash Transfer Programming in humanitarian Aid, Australia

vii. GOK (2010) Constitution of Kenya, Laws of Kenya 2010, Nairobi, Kenya: Amkeni Wa Kenya. Website: kenyalaw.org

viii. GOK (2011) Kenya Social Protection Policy. Nairobi: Ministry of Gender, Children and Social Development.

ix. GOK (2011) Kenya Social Protection Policy. Website: www.gender.co.ke

x. $\quad$ GOK (2012) Kenya Social Protection sector. Website: www.planning.co.ke

xi. GOK (2013) Social Assistance Act 2013. Nairobi Kenya: National Council for Law Reporting

xii. GOK (2014) National Emergency response plan and Standard Operating Procedures, Nairobi; Kenya, Ministry of Interior and Coordination of National Government.

xiii. GOK (2017) National DRM policy 2017; Nairobi, Kenya: National Council for Law Reporting

xiv. GOK. (2008). National Social Protection Strategy. Nairobi, Kenya: Ministry of Gender, children and Social Developmentp.43

xv. INFRC (2014) Guidelines for Cash Transfer Programming, Geneva, Switzerland

xvi. Kaufmann, D. (2012). Comparative study of Emergency Cash Coordination Mechanisms. New York: CaLP

xvii. Kerry, S. Lourdes, F. \& Nelia, T. (2012). Transforming Cash Transfers: Beneficiary and Community Perspectives on Social Basic Subsidy Programme in Mozambique, London, UK. Overseas Development Institute.

xviii. Marito, and G., Charity, M. (2012) The cash dividend: The rise of Cash Transfer Programs in Sub Saharan Africa, Retrieved on $21^{\text {th }}$ November, 2018 from https/ opeknowledge.worldbank.org

xix. NDMA (2016) Turkana county Steering Group Report, Lodwar, Kenya

xx. TCG (2016). Turkana County Emergency and Disaster Management Act 2016, Nairobi: Government printers, Nairobi. Retrieved on 13th September, 2019 from www.klrc.go.ke

xxi. World Bank (2016). Strategic Note:Cash Transfer in Humanitarina Context. World bank, Interagency Standing Committee. Washington DC: World Bank Publisher Office. 